\section{OP0243 PREDICTORS OF REMISSION AT WEEK 12 IN PATIENTS WITH NON-RADIOGRAPHIC AXIAL SPONDYLOARTHRITIS RECEIVING OPEN-LABEL ADALIMUMAB TREATMENT IN THE ABILITY-3 STUDY}

J. Sieper ${ }^{1}$, R. Landewé ${ }^{2}$, M. Magrey ${ }^{3}$, J.K. Anderson ${ }^{4}$, S. Zhong ${ }^{4}$, X. Wang ${ }^{4}$, A. Lertratanakul ${ }^{4} .{ }^{1}$ Charité Universitätsmedizin Berlin, Berlin, Germany; ${ }^{2}$ University of Amsterdam, Amsterdam, Netherlands; ${ }^{3}$ Case Western Reserve University School of Medicine at MetroHealth Medical Center, Cleveland; ${ }^{4}$ AbbVie, North Chicago, United States

Background: Patients (pts) with non-radiographic axial spondyloarthritis (nraxSpA) who fail nonsteroidal anti-inflammatory drug (NSAID) therapy are candidates for tumor necrosis factor inhibitor (TNFi) therapy if they have objective signs of inflammation. Baseline predictors of response to TNFi therapy, including remission, may aid clinical management.

Objectives: Describe baseline predictors of remission in nr-axSpA at wk 12 of open-label adalimumab (ADA) therapy in the ABILITY-3 study.

Methods: ABILITY-3 enrolled adult pts with nr-axSpA (fulfilling Assessment of SpondyloArthritis international Society [ASAS] criteria but not modified New York criteria) with moderately to severely active disease at screening and baseline, objective evidence of inflammation in the sacroiliac $(\mathrm{SI})$ joints or spine on magnetic resonance imaging (MRI) or elevated high-sensitivity C-reactive protein (hs-CRP; defined as $>$ upper limit of normal for the lab) at screening, and an inadequate response to $\geq 2$ NSAIDs. Eligible pts received ADA $40 \mathrm{mg}$ every other week during a 28-wk open-label lead-in period. Clinical remission was defined as Ankylosing Spondylitis Disease Activity Score inactive disease (ASDAS ID; score $<1.3$ ) or ASAS partial remission (score $<2 / 10$ in each of the 4 ASAS domains). Stepwise logistic regression was used to identify potential baseline predictors of remission at wk 12.

Results: 673 pts were enrolled (Table). Lower disease activity, increased inflammation (morning stiffness), less functional limitation (BASFI), younger age, presence of human leukocyte antigen-B27 (HLA-B27), and positive MRI of the SI joints were the strongest predictors of ASDAS ID; higher hs-CRP levels, younger

Table 1. Baseline Characteristics

\begin{tabular}{|c|c|c|c|c|}
\hline \multirow[t]{2}{*}{ Mean \pm SD or $n(\%)$} & \multicolumn{2}{|c|}{ ASDAS ID } & \multicolumn{2}{|c|}{ ASAS PR } \\
\hline & $\begin{array}{c}\text { Responders } \\
(\mathrm{n}=211)\end{array}$ & $\begin{array}{c}\text { Non-responders } \\
(\mathrm{n}=389)\end{array}$ & $\begin{array}{c}\text { Responders } \\
(n=133)\end{array}$ & $\begin{array}{c}\text { Non-responders } \\
(n=470)\end{array}$ \\
\hline Age, y & $33.6 \pm 9.7$ & $38.9 \pm 11.4$ & $31.8 \pm 8.7$ & $38.5 \pm 11.2$ \\
\hline Diagnosis duration, y & $1.7 \pm 2.9$ & $1.8 \pm 3.6$ & $1.7 \pm 2.9$ & $1.7 \pm 3.2$ \\
\hline Symptom duration, y & $6.1 \pm 6.2$ & $8.2 \pm 8.1$ & $5.3 \pm 5.7$ & $8.0 \pm 7.8$ \\
\hline HLA-B27 positive & $183(87)$ & $274(70)$ & $119(89)$ & $340(72)$ \\
\hline ASDAS & $3.4 \pm 0.8$ & $3.7 \pm 0.8$ & $3.7 \pm 0.9$ & $3.6 \pm 0.8$ \\
\hline Inflammation* ${ }^{*}$ & $6.9 \pm 1.8$ & $7.0 \pm 2.0$ & $6.9 \pm 1.9$ & $7.0 \pm 1.9$ \\
\hline Patient global assessment of pain & $7.0 \pm 1.7$ & $7.7 \pm 1.5$ & $7.1 \pm 1.9$ & $7.5 \pm 1.6$ \\
\hline hs-CRP & $9.0 \pm 13.1$ & $10.9 \pm 16.8$ & $15.5 \pm 21.3$ & $8.8 \pm 13.1$ \\
\hline BASFI & $4.6 \pm 2.2$ & $5.7 \pm 2.2$ & $4.9 \pm 2.4$ & $5.4 \pm 2.2$ \\
\hline HAQ-S & $1.9 \pm 0.5$ & $2.2 \pm 0.5$ & $1.9 \pm 0.6$ & $2.1 \pm 0.5$ \\
\hline MRI SI joints positive & $165(78)$ & $262(67)$ & $102(77)$ & $328(70)$ \\
\hline MRI spine positive & $59(28)$ & $114(29)$ & $47(35)$ & $126(27)$ \\
\hline
\end{tabular}

BASFI, Bath Ankylosing Spondylitis Functional Index; HAQ-S, Health Assessment Questionnaire modified for the Spondyloarthropathies. *Mean of Bath Ankylosing Spondylitis Disease Activity Index (BASDAI) questions 5 and 6 (scale, $0-10$ ).

Figure. Results From Final Stepwise Multivariate Regression Model

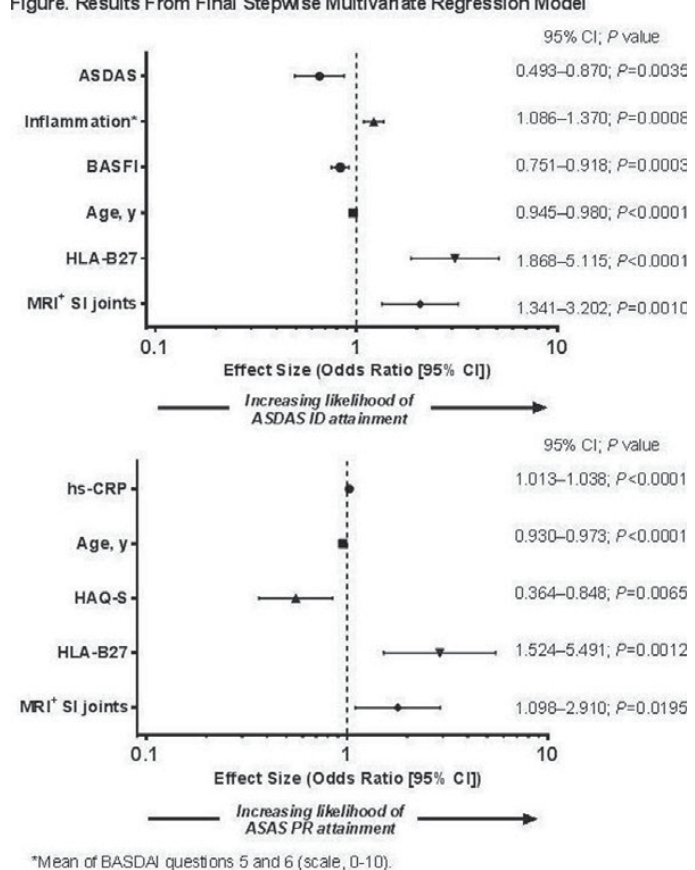

age, lower functional status (HAQ-S), presence of HLA-B27, and positive MRI of the SI joints were the strongest predictors of ASAS PR (Figure).

Conclusions: In ABILITY-3, younger age, better functional status, presence of HLA-B27, and positive MRI of the SI joints consistently predicted clinical remission at wk 12 of open-label ADA treatment in pts with nr-axSpA.

Acknowledgements: AbbVie funded the study and approved the abstract for submission. Medical writing support was provided by Maria Hovenden, PhD, of Complete Publication Solutions, LLC (North Wales, PA) and was funded by AbbVie.

Disclosure of Interest: J. Sieper Grant/research support from: AbbVie, Merck, Pfizer, and UCB, Consultant for: AbbVie, Merck, Pfizer, and UCB, Speakers bureau: AbbVie, Merck, Pfizer, and UCB, R. Landewé Grant/research support from: Abbott, Amgen, Centocor, Novartis, Pfizer, Roche, Schering-Plough, UCB, and Wyeth, Consultant for: Abbott/AbbVie, Ablynx, Amgen, Astra-Zeneca, Bristol Myers Squibb, Celgene, Janssen (formerly Centocor), Galapagos, GlaxoSmithKline, Novartis, Novo-Nordisk, Merck, Pfizer, Roche, Schering-Plough, TiGenix, $\mathrm{UCB}$, and Wyeth, Speakers bureau: Abbott/AbbVie, Amgen, Bristol Myers Squibb, Janssen (formerly Centocor), Merck, Pfizer, Roche, Schering-Plough, UCB, Wyeth; he is director of Rheumatology Consultancy BV, a registered Dutch company., M. Magrey Grant/research support from: Amgen, AbbVie, and UCB Pharma, Consultant for: UCB and Janssen, J. Anderson Employee of: AbbVie, S. Zhong Employee of: AbbVie, X. Wang Employee of: AbbVie, A. Lertratanakul Employee of: AbbVie

DOI: 10.1136/annrheumdis-2017-eular.6467

\section{OP0244 FAMILY MATTERS: VALUE OF FAMILY HISTORY OF SPONDYLOARTHRITIS IN THE DIAGNOSTIC WORK-UP OF PATIENTS WITH CHRONIC BACK PAIN: RESULTS FROM THE SPACE AND DESIR COHORTS}

Z. Ez-Zaitouni ${ }^{1}$, A. Hilkens ${ }^{1}$, L. Gossec ${ }^{2}$, I.J. Berg ${ }^{3}$, R. Landewé ${ }^{4}$,

R. Ramonda ${ }^{5}$, M. Dougados ${ }^{6}$, D. van der Heijde ${ }^{1}$, F. van Gaalen ${ }^{1}$.

${ }^{1}$ Rheumatology, Leiden University Medical Center, Leiden, Netherlands; ${ }^{2}$ UPMC University Paris 06, Paris, France; ${ }^{3}$ Rheumatology, Diakonhjemmet Hospital, Oslo, Norway; ${ }^{4}$ Rheumatology, Academic Medical Center, Amsterdam, Netherlands; ${ }^{5}$ Rheumatology Unit, DIMED, University of Padova, Padova, Italy; ${ }^{6}$ Rheumatology, Université Paris Descartes, Hôpital Cochin, Assistance Publique-Hôpitaux de Paris, INSERM (U1153): Epidémiologie Clinique et Biostatistiques, PRES Sorbonne Paris-Cité, Paris, France

Background: A positive family history (PFH) of spondyloarthritis ( $\mathrm{SpA}$ ) is considered a risk indicator for the presence of axial spondyloarthritis (axSpA) in patients with chronic back pain (CBP). In the ASAS classification criteria, a $\mathrm{PFH}$ of SpA is defined as the presence of any of the following diseases in firstor second-degree relatives: ankylosing spondylitis (AS), acute anterior uveitis $(A A U)$, reactive arthritis (ReA), inflammatory bowel disease (IBD), and psoriasis. It is however not known if a PFH for each of these diseases contributes equally well to making a diagnosis of axSpA in patients presenting with CBP.

Objectives: To assess which SpA diseases in family members are associated with HLA-B27 and axSpA in patients with CBP.

Methods: The SPACE cohort includes patients with CBP ( $\geq 3$ months, $\leq 2$ years, onset $<45$ years) from various European rheumatology centers. DESIR is a French prospective multicenter cohort of patients with inflammatory back pain (IBP; $\geq 3$ months, $<3$ years, onset $<50$ years), suggestive of axSpA. Patients underwent a full diagnostic work-up at baseline including MRI and radiographs of sacroiliac joints (local reading), laboratory assessments (e.g. HLA-B27), and assessment of all other SpA features. Patients were asked about the presence of $\mathrm{SpA}$ diseases in first- or second-degree relatives (AS, AAU, ReA, IBD, and psoriasis). The associations between a PFH and HLA-B27, sacroiliitis, axSpA diagnosis by the rheumatologist, and fulfilment of the ASAS classification criteria in CBP patients were assessed.

Results: In 438 patients from the SPACE cohort and 647 patients from the DESIR cohort, a PFH of AS (odds ratio (OR) 5.9 (3.5-9.9) and OR 3.3 (2.1-5.2), respectively for SPACE and DESIR) and a PFH of AAU (OR 9.8 (3.3-28.9) and OR $21.6(2.9-160.1))$ were significantly associated with presence of HLA-B27 (Table 1).Furthermore, in both cohorts a PFH of AS and a PFH of AAU were positively associated with fulfilment of the ASAS-criteria, but not with sacroiliitis on imaging (data not shown). In SPACE, but not in DESIR, a PFH of AS or AAU was associated with axSpA diagnosis (data not shown). In both cohorts, a PFH of ReA, IBD, or psoriasis was not positively associated with HLA-B27 positivity, sacroiliitis on imaging, axSpA diagnosis or meeting the ASAS criteria for axSpA. Conclusions: In two recent CBP cohorts, a PFH of ReA, IBD, or psoriasis did not

Table 1 Association of family history manifestations with HLA-B27 in patients with chronic back pain in the SPACE cohort ( $n=438$ ) and in patients

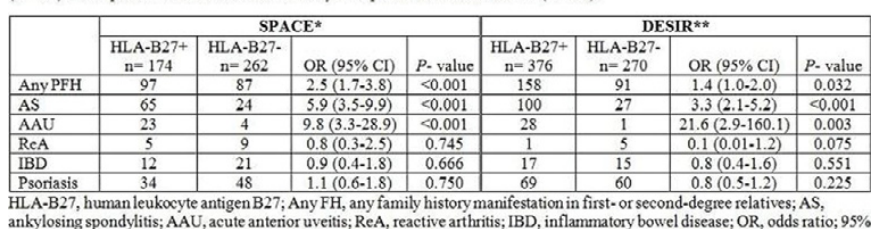
ankylosing spondylitis; $\mathrm{AAU}$, acute anterior uveitis; ReA, reactive arthritis; $\mathrm{IBD}$, inflammatory bowel disease; $\mathrm{OR}$, odds $\mathrm{CI}, 95 \%$ confidence interval. ${ }^{*} 2$ patients with unknown HLA-B27 status; $* 1$ with patient unknown HLA-B27 status. 
contribute to identifying axSpA in CBP patients indicating these family elements may not be very useful for diagnosis. A PFH of AS or AAU however may be useful in finding cases in low prevalence settings as these were correlated with HLA-B27 carriership.

Disclosure of Interest: None declared

DOI: 10.1136/annrheumdis-2017-eular.4671

\section{OP0245 EMPLOYMENT PERSPECTIVES OF PATIENTS WITH ANKYLOSING SPONDYLITIS IN THE BIOLOGICS ERA}

C. Webers ${ }^{1,2}$, L. Vanhoof ${ }^{1}$, S. van Genderen ${ }^{1,2}$, G. Plasqui ${ }^{3}$, L. Heuft ${ }^{4}$, M. van ${\text { de } \text { Laar }^{5} \text {, J. Luime }}^{6}$, D. van der Heijde ${ }^{7}$, A. Spoorenberg ${ }^{8}$, A. Boonen ${ }^{1,2}$. ${ }^{1}$ MUMC; ${ }^{2}$ CAPHRI; ${ }^{3}$ Human Biology, UM, Maastricht; ${ }^{4}$ Laurentius, Roermond; ${ }^{5}$ MST, Enschede; ${ }^{6}$ Erasmus MC, Rotterdam; ${ }^{7}$ LUMC, Leiden; ${ }^{8}$ UMCG, Groningen, Netherlands

Background: In the pre-biologics era, employment of patients with ankylosing spondylitis (AS) was decreased when compared to the general population. However, information on standardized employment since the introduction of biologicals is lacking. Also, while mastery (control over disease) has been identified as strong predictor of work outcome within patients with AS, it is not known whether such personality trait plays a similar role in patients compared to population subjects.

Objectives: To update the knowledge on employment and contributing factors, in particular personal factors, among Dutch patients with AS compared to general population subjects.

Methods: Data from patients and population controls participating in the Dutch cross-sectional multicenter survey-based Social Participation in AS Study (SPASS) and $\leq 65$ years were used. Standardized employment ratios (SERs) were calculated using indirect standardization after adjusting for age, gender and education and were stratified by disease duration tertiles. Adjusted absolute employment rate (\%) was calculated as "SER[AS] ${ }^{*}$ employment rate [controls]". Modified Poisson regressions were performed to understand the role of mastery as a personal factor (Pearlin's Mastery scale) in patients opposed to controls, independent of socio-demographics (age, gender, education) and health-related factors (comorbidities, Physical Component Summary (PCS) of the SF-36).

Results: 214 patients and 470 controls (127 [59.3\%] and 323 [68.7\%] males; mean age of 48.3 [SD 10.4] and 39.3 [SD 12.7] years, respectively) completed the online questionnaire in 2011. SERs $(95 \% \mathrm{Cl})$ of patients with AS with controls set as reference $(1.00)$ were $0.83(0.69-0.98)$ for the total group, 0.84 [0.67-1.04] for males and 0.83 [0.59-1.07] for females. There was no significant difference in SER between those with short or long disease duration (Figure 1). Adjusted absolute employment rate (\%) of patients with AS was $14 \%$ lower compared to controls ( $69 \%$ vs. $84 \%$ ). In both patients and controls, higher PCS (SF-36) was associated with being employed. While AS patients with higher (better) mastery were more likely to be employed, such association was not seen in controls $\left(\mathrm{p}<0.01\right.$ for interaction group ${ }^{*}$ mastery) (Table).

Table 1. Multivariate Poisson regression exploring determinants of work participation, stratified by group (AS vs. controls)

\begin{tabular}{lccccccc}
\hline Variable & \multicolumn{3}{c}{$\mathrm{AS}(\mathrm{n}=213)$} & & \multicolumn{3}{c}{ Controls $(\mathrm{n}=465)$} \\
\cline { 2 - 4 } \cline { 7 - 8 } & IRR & $95 \% \mathrm{Cl}$ & $\mathrm{p}$ & & IRR & $95 \% \mathrm{Cl}$ & $\mathrm{p}$ \\
\hline Age, years & 0.99 & $0.98-1.00$ & $<0.01$ & & 1.00 & $0.99-1.00$ & 0.07 \\
Gender, male & 1.13 & $0.91-1.39$ & 0.26 & & 1.08 & $0.99-1.19$ & 0.09 \\
Education, high & - & & $\mathrm{ns}^{\dagger}$ & & 1.09 & $1.01-1.18$ & 0.02 \\
Comorbidity (SCQ, 0-39) & 0.97 & $0.94-1.01$ & 0.12 & & 0.97 & $0.94-1.01$ & 0.14 \\
SF-36 PCS (0-100) & 1.02 & $1.00-1.03$ & $<0.01$ & & 1.01 & $1.00-1.02$ & 0.02 \\
Mastery (7-28) & 1.03 & $1.00-1.05$ & 0.03 & & - & & $\mathrm{ns}^{\dagger}$
\end{tabular}

†Value not significant and no confounder.

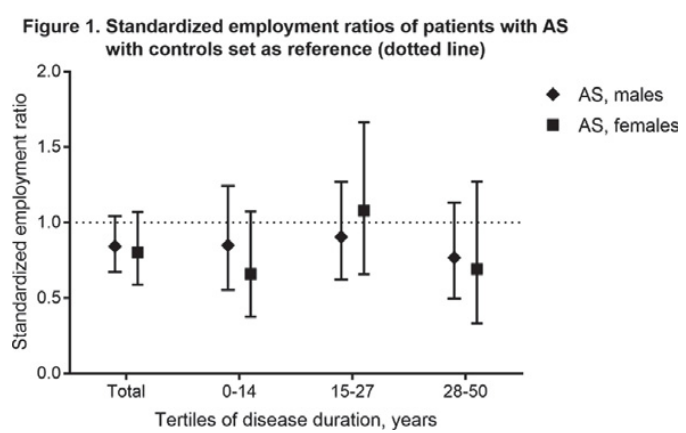

Conclusions: In the biologics era, employment among Dutch patients with AS remains reduced when compared to the general population, also in those with less than 15 years disease duration. As mastery in patients is independently associated with work outcome, it is worthwhile exploring whether improving personal self-management skills supports future worker participation.

Disclosure of Interest: None declared

DOI: 10.1136/annrheumdis-2017-eular.3472
FRIDAY, 16 JUNE 2017

RA - causes and courses

\section{OP0246 IMPACT OF DISEASE ACTIVITY MEASURES ON SICK LEAVE IN BIOLOGICS-TREATED PATIENTS WITH RHEUMATOID ARTHRITIS: OBSERVATIONAL DATA FROM SOUTHERN SWEDEN}

J.K. Wallman $^{1}$, J.K. Söderling ${ }^{2}$, A. Gülfe ${ }^{1}$, L.-E. Kristensen ${ }^{3}$, M. Neovius ${ }^{2}$, T. Olofsson ${ }^{1}$. 'Lund University, Department of Clinical Sciences Lund, Rheumatology, Lund; ${ }^{2}$ Karolinska Institutet, Department of Medicine, Clinical Epidemiology Unit, Stockholm, Sweden; ${ }^{3}$ The Parker Institute, Department of Rheumatology, Copenhagen University Hospital, Frederiksberg and Bispebjerg, Denmark

Background: Sick leave generally represents the earliest phase of work-loss in rheumatoid arthritis (RA) patients, often on the trajectory towards more permanent disability pension. Sick leave may still change with disease activity fluctuations and is thus potentially reversible and accessible for interventions. However, data remain scarce on the importance of modifiable, non-composite disease activity measures for subsequent sick leave in RA patients treated with biologics.

Objectives: To study the impact of common, non-composite disease activity measures on sick leave in biologics-treated RA patients.

Methods: Study visits of biologics-treated RA patients of working-age $(<65 \mathrm{y})$ without disability pension, monitored in the population-based, observational South Swedish Arthritis Treatment Group register 2005-2011, were included (5151 visits; 957 patients). We performed association analyses between various non-composite disease activity measures at each visit and number of objectively assessed sick leave days during the month thereafter, retrieved from the Social Insurance Agency. Separate generalised estimating equation regression models were used, adjusting for age, sex, educational level, disease duration, number of previous biologics, time from start of the present biologic, and calendar year of study visit. Analyses were furthermore stratified on sick leave status the month preceding each visit (no sick leave $=0$ days out of 30 ; partial sick leave $=1-29$ days and full sick leave $=30$ days) and results are presented as standardised beta coefficients for comparability, with bootstrap-generated $95 \%$ confidence intervals. The composite 28-joint disease activity score (DAS28) and the health assessment questionnaire (HAQ) disability score were included as contrast.

Results: Out of common, non-composite disease activity measures, visual analogue scale (VAS) global and VAS pain were most strongly associated with sick leave days the month after the study visit, irrespective of baseline sick leave status (Figure). Generally, the more objective measures (erythrocyte sedimentation rate, C-reactive protein and swollen joint count (SJC)) had less impact on subsequent sick leave than the more subjective variables (VAS global, VAS pain, evaluator's global and tender joint count (TJC)). As expected, HAQ showed the strongest association.

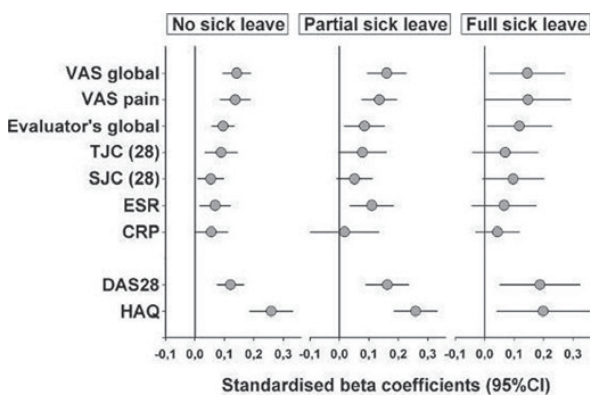

Conclusions: More subjective disease activity measures have greater impact on sick leave in biologics-treated RA patients than do more objective variables, suggesting a stronger focus on the former ones when targeting work-loss or intervening to reduce it.

Disclosure of Interest: J. Wallman Consultant for: Novartis, Celgene and UCB, J. Söderling Grant/research support from: Participated in previous research projects fully or partly funded by Novo Nordisk and Combine Sweden, Consultant for: Served as an external consultant to AbbVie, Merck and Novartis, A. Gülfe: None declared, L.-E. Kristensen Grant/research support from: Oak Foundation, Consultant for: AbbVie, Celgene, BMS, MSD, Novartis, Pfizer, UCB, M. Neovius Grant/research support from: Participated in research projects fully or partly funded by Schering-Plough, AstraZeneca, Novo Nordisk, Pfizer and Roche (unrelated to the current work), Consultant for: Participated in advisory boards for Pfizer (rheumatology) and Abbott (non-rheumatology), T. Olofsson: None declared

DOI: 10.1136/annrheumdis-2017-eular.2883 